\title{
Dicotomia entre homens bons e maus
}

Ivo Gabriel Repczuk

AUTOR: Ivo Gabriel Repczuk;

TITULAÇÃO: Licenciado em Letras pela Uninter (Centro Universitário Internacional Uninter), estudante de Criminologia;

TíTULO: Dicotomia entre homens bons e maus;

AREA DE INTERESSE: Direito;

ENDEREÇO: Rua Jose Laurindo de Souza, 1181, Cidade Industrial, Curitiba, Paraná, CEP 81460315;

EMAIL: ivogabriel994@gmail.com;

FONE: 47997301264;

Este trabalho não esta vinculado a qualquer instituição de ensino, apenas tem por objetivo obter o certificado com o dói, e não tem nenhum tipo de beneficio de qualquer fonte. 


\title{
DICOTOMIA ENTRE HOMENS BONS E MAUS
}

\author{
DICHOTOMY BETWEEN GOOD GUYS AND BAD GUYS \\ DICOTOMÍA ENTRE BUENOS Y MALOS
}

Ivo Gabriel Repczuk*

Resumo: esse artigo buscou dar uma explicação lógica para o fato criminoso, por que as pessoas cometem crimes, além da finalidade do controle social do comportamento delitivo, a vítima que na maioria das vezes e deixada de lado pelo estado, que é responsável pelo controle social foral do crime por meio da polícia. Ou seja, o objeto de estudo são os elementos de estudo da criminologia como crime, criminoso, vítima e controle social. Principal resultado encontrado e que não podemos devir os pesos entre boas e, mas, por que todas as pessoas fazem o bem, mas fazem o mal também.

Palavras-chave: Criminologia; Direito; Justiça.

Abstract: This article sought to give a logical explanation for the fact criminal, why people commit crimes, in addition to the purpose of the social control of criminal behavior, the victim most often and left out by the State, which is responsible for controlling Social Charter of crime by police. That is, the object of study is the elements of study of Criminology as a crime victim, criminal, and social control. Main result found and we can't come between good and weights, but for all people to do good, but they're evil too.

Keywords:Criminology; right,

justice.

Resumen: Este artículo busca dar una explicación lógica para el criminal hecho, por qué personas cometen crímenes, además de la finalidad del control social del comportamiento criminal, la víctima más a menudo y a la izquierda hacia fuera por el estado, que es responsable de controlar Carta Social de la delincuencia por la policía. Es decir, el objeto de estudio son los elementos de estudio de la criminología como un control de la víctima, delito penal y social. Los resultados principales encontrados y no podemos venir entre buena y pesos, pero para todas las personas a hacer el bien, pero son malos.

Palabrasclave:Criminología;derecho, justicia. 
O problema trabalho no artigo se refere aos elementos da criminologia, o comportamento humano em sociedade e o funcionamento do aparato repressivo do estado sua função e definições próprias da criminologia. Além de propostas e críticas para se aplicar a justiça brasileira, os problemas do Brasil, quais as vítimas no cenário brasileiro. Além disso, e tratado de modo breve questão do controle social informal que possui muito poder de peruca na formação de valores nas pessoas e no corpo social.

\section{MÉTODOS}

Os dados que serviram de base para a produção deste artigo foram artigos sobre criminologia, matérias de noções básicas de criminologia do de apostilas de concurso, e buscas na internet, a população estudada e a população em geral, pois quando e fala em elementos da criminologia se busca dar explicações para eventos criminológicos amplos a ponto de abarcar qualquer fato criminoso. A análise dos fatos sociais teve como arcabouço para o método empírico, onde diversos fatores servem para que qualquer alegação fosse feita, não foi uma mera presunção.

Não foram utilizadas cobaias, nem interrogatórios de pessoas, não foram citados nomes nem fatos que envolvem pessoas comuns, o objetivo do trabalho foi trazer algo novo, mas sempre com respeito à vida, a justiça e a igualdade. Não devemos interpretar s firmações deste trabalho para justificar qualquer ato que atente contra os valores sociais, ou contra qualquer religião ou forma de pensar que devem ser respeitadas.

\section{RESULTADOS E DISCUSSOES}

Criminologia e a ciência empírica e interdisciplinar que estuda o crime, criminoso, controle social do comportamento delitivo e a vítima. E interdisciplinar porque várias áreas do saber contemplam se campo de estudo como direito, medicina legal, psicologia, biologia, etc.

Como todos sabem, nem sempre os seres humanos viveram em grupo, no início não existiam grandes aglomerações de pessoas, a natureza castigava o homem, que vivi só em busca de brigo e alimento, mas o que tem a ver o homem primitivo com criminologia, com o criminoso. Primeiro temos que voltar às origens para entender o que é o crime, antes de existir as cidades, vilas, e até podem ser consideradas aqui como aglomerações de pessoas apenas para fim de entender o homem primitivo cometia condutas que são para o atual meio sociais considerados como crime fazia tudo o que fosse preciso para sobreviver, e claro que caso vivesse em grupos menores de homens primitivos de alguma forma interagisse de modo positivo, sem violência, até com sentimentos inerentes a pessoa humana. Bom para que tudo isso, 
a história pode explicar o que é o crime, bom com o surgimento das primeiras aglomerações de pessoas, pela necessidade de sobrevivência e que paulatinamente surgiram os códigos de convivência social, foi definido o que é bom, o que e ruim, a religião, e o que deve ser considerado errado, ruim, e merece o repudio do corpo social pela necessidade da ordem e do bem comum da sociedade. Na criminologia critica temos a Teoria do etiquetamento social segundo Alessandro Baratta não há conduta naturalmente delitiva ou pessoa puramente criminosa.

Da para considerar como verdade que o crime não passa de uma etiqueta, as pessoas decidem que ligo e ruim para as pessoas, afeta algum bem jurídico, e estabelecem punições por meio do aparato repressivo do estado. Ate que quem estuda criminologia não vê nada de novo, mas se o crime e uma etiqueta um rotulam a sociedade por uma necessidade lógica estabeleceu o certo e o errado, no perguntamos, quem comete um crime e alguém pior que as pessoas que não cometem crimes, e um doente como pregam a escola Positivista da criminologia. A explicação e que a pessoa que comete um crime, não tem nada de especial em relação às outras pessoas, apenas praticou uma conduta reprovável pelo corpo social.

Para entender a definição de criminoso temos que levar em consideração que as pessoas não podem ser divididas entre, más e boas, qualquer pessoa de meia idade, já fez coisas boas, ruins, do ponto de vista social, não quis dizer que cometeu crime, mas que fez algo considerado reprovável pelo corpo social, que atualmente possui infinitas leis, regras de conduta informais em escolas, igrejas, nos locais de trabalho e até nas prisões.

Mas não quer dizer que seja válido adotar o abolicionismo penal, que prega uma sociedade sem leis sem repressão estatal só a liberdade reinaria, pois não tem como unir qualidade de vida, progresso e meritocracia sem regras. Diversas vezes vemos nos noticiários greves de policiais que por paralisarem os serviços, ocorrem até arrastões em lojas. Se não houvesse nenhum tipo de lei o controle do comportamento delitivo só o caos iria reinar.

As regras sociais podem mudar com o tempo, como no Brasil o adultério era crime e deixou de serem, muitas vezes as leis mudam pelo simples fato de mudar de governo, questões políticas afetam muito as ações de repressão do crime. Mais um questionamento que pode ser feito se o crime tem seu viés político, então não quer dizer que o criminoso e um ser inferior que deve ser socializado, apenas foram contra a hegemonia e o poder do estado, no Brasil o estado e considerado como sujeito passivo em todos os crimes.

E se o criminoso surge da etiqueta que é posta pelo estado, ou seja, alguém que comete algo ilegal perante a sociedade, o que é a vítima, quais são os processos que fazem vitimas. Bom as vítimas podem ser conceituadas como pessoas que figuram como sujeito passivo de um crime, tem algum bem jurídico lesado por uma conduta considerada crime pelo estado e pelo corpo social.

O lado ruim do governo e quando ele interviria de modo errado na vida das pessoas, como os jovens e crianças que só doutrinados nas escolas, o governo que propala ideologias de defesa de criminosos, formam valores ruins. Existe no Brasil muita desigualdade e miséria, desemprego, em parte relacionada à automação industrial, a substituição da Mao de obra humana pelas maquinas e a 
racionalização do trabalho, isso e algo inevitável, o progresso não pode ser freado, nem a ganância das pessoas, quanto a isso não da pra ter boas perspectivas de futuro.

Segundo Sergio Salomao Shecaira, existem controles formais e informais do controle social do comportamento delitivo, o controle formal corresponde às regras ou leis institucionais, como o código penal no Brasil, já o controle informal pode ser entendido como crenças e costumes apesar das classificações ambas têm em comum que são existem no corpo social, uma pessoa que convive com o meio social precisa desenvolver suas habilidades sociais como a empatia, o respeito e seguir as regras sociais. Se todas as regras de comportamento e leis são sociais, então e seguro presumir que eles não são justas nível universal, apenas existem PT mera necessidade social, as pessoas que cometem desvios de conduto são doentes, loucas, penas não form. socializadas corretamente, tal processo de socialização não deve ser visto como algo natural, pois se fosse natural não precisaríamos de coerção ou esforço, as regras sociais seriam incorporadas a conduta humana como um instinto nato.

O processo de socialização serve como uma form. de dominar as pessoas, torna dócil, para que cumpram seu papel social, e fácil de entender porque na maioria das vezes, os malandros no Brasil se do bem, muito simples, porque uma regra muito importante de funcionamento saudável do corpo social e a igualdade e justiça, como exemplo posso citar as cotas raciais qual promovem a desigualdade, ou seja, estabelece uma forma de acesso às universidades e cargos públicos sem mérito penas com base na cor. Este é apenas um exemplo da violação da meritocracia, muito simples o que evita a barbárie nem sempre e o controle social formal por meio das forcas de segurança do estado, mas uma diretriz de ação do governo que garanta o sucesso pessoal com o esforço a edição e o mérito. Seguir a lei é trabalhar duro, deveria ser valorizado, atividades que contribuam com o bem comum deveriam ser premiadas pelo corpo social, na maioria das vezes o que prevalece mesmo e a injustiça.

Um fato social interessante de ser discutido e vontade que as pessoas têm em ter os outros e atribuir culpa para qualquer coisa como aplicar um preço por um crime, ser que as pessoas gostam de punir pessoas que cometem crimes porque punição é divina e justa ou pelo simples fato de sentirem prazer em fazer o outro pagar por algo que nem diz respeito à pessoa que pune.

O que e instinto nato, um exemplo e o cachorro da raça pastor alemão, este animal já e predisposto em nível genético, a ser um animal bom par adestrar, pode ser usado pela policia, como cão que, diferente de um cachorro da raça pinscher que não tem vocação par ser um cão que, nós seres humanos apesar de sermos capazes de agir com inteligência também temos instintos, somos predispostos desde que nascemos à praticar condutas de diversas naturezas, dentre as muitas predisposições, esta a predisposição de cometer crimes, ser cruel, usar os outros, durante historia temos muitos casos de exploração do homem pelo homem, a escravidão, os homicidas que são citados até na bíblia desde os tempos antigos, no final das contas o nosso instinto e ser cruel, ser ruim com base nos padrões sociais, a única seus que torna um ser humano bom é o convívio com outras pessoas.

Então a vida não e como filme americano onde o criminoso e o único vilão, ele e totalmente cruel e quem segue lei e os códigos de conduta social são seres dotados somente de amor e bondade no coração. Pessoas mais espertas escondem a vida privada, por exemplo, no ambiente de trabalho, com 
desconhecidos, não e aconselhável falar de pretensões da vida e qualquer coisa que as pessoas possam usar contra, pois e isso que as pessoas fazem, quando tomam conhecimento de alguma informação, a pergunta na cabeça do malandro, como eu posso usar esta informação a meu favor. A mídia ganha à vida difamando políticos, pessoas famosas, então como vemos não e nada bom ser famoso, pois a pessoa tem o velho costume de julgar os outros, ninguém se pune pelos seus erros, mas gosta de punir os outros quando erram, porque desta forma, taxando outras pessoas com seus erros e que se aumenta o prestigio perante o povo, um exemplo e o que ocorre nas pra ganhar uma promoção, começar a espalhar medo e exaltar o erro do concorrente, o mesmo acontece na política, à maioria dos políticos não seguem a lei a risca, ai quando encontram uma falha do seu concorrente, o entregam pra justiça.

Temos o controle formal, aí podemos citar a polícia, e o poder judiciário que age quando alguma lei e violada. A repressão policial em qualquer sociedade organizada e com perspectiva de futuro tem que ser ativa, pois a certeza da repressão já garante um convívio pacifico, ou melhor, razoavelmente pacifico, tornando possível o progresso, o caos e um mundo sem leis hoje em dia pela grande quantidade de pessoas não é viável abolir a repressão e o controle social por parte do estado quando legal e democraticamente constituído. Mas deve-se ter em mente que nenhum tipo de controle social deve ser visto como algo divino e justo aos olhos de Deus, mas uma mera necessidade.

O Brasil e o mundo atualmente é capitalista e a maioria dos políticos são grandes empresários, são sindicalistas, pessoas que possuem bastante dinheiro e influencia a polícia e subordinada ao governador, existem duas policia, a militar e a civil, esta última está bem defasada, a resposta e bem simples, nenhum político gosta de policial que tem por missão apurar infrações penais, sair por ai investigando, mexendo na sujeira, daí a polícia civil vive com falta de efetivo, já militar abre muito concurso e no final das contas o cidadão quando e vítima de um crime, vai pra cifra negra, ou seja, fica refém um estado que criou um sistema corrupto e no final das contas, nada de investigação, quem foi assaltado, agredido, tem um familiar desaparecido ou morto sabe que a polícia civil não vence investigar tudo, ou a lei criou empecilhos, além da malandragem do policial, eu mesmo já fui assaltado, apresentei as provas e a polícia se manteve inerte, ai eu pensei, e eu tivesse sido morto, ficaria à revelia da lei, ficaria na impunidade.

Como minimizar os problemas das cifras negras que são hoje em dia está em nível caótico, o descaso da polícia e muito grande, a polícia brasileira é muito ineficiente para reprimir greves ou pegar alguém em flagrante, mas quando precisa de algum tipo de investigação aí já era, a única certeza e a impunidade. Como resolver este problema, fazendo uma polícia civil, com poderes de investigar e reduzir o efetivo da polícia militar ao mínimo necessário para agir quando o crime está em flagrância. Mas só isso não bastaria, pois o sistema legal inviabiliza as investigações, então se houvesse boa vontade o que e quase impossível, poderia ampliar os mecanismos legais de investigação, outro problema e o judiciário que usurpou a função de apurar infrações penais, ai contratam técnicos administrativos e estagiários que fazem funções similares a dos escrivães e investigadores, isso e mais bato garante emprego para "os amigos", mas onde está o problema nisso, muito simples, quando alguém relata um fato criminoso a um investigador um policial que tem poder de investigar e tem boa vontade, e mais fácil evitar a impunidade, agora relate um fato criminoso a um estagiário, ele vai escrever o relatório e jogar numa gaveta, te alguém tomar uma 
atitude não tem mais bem jurídico pra salvar, nem criminoso para encontrar. Cifra negra segundo Edwin $\mathrm{H}$. Sutherland se refere aos crimes que no são solucionados pelo aparato policial do estado e nem chegam ao conhecimento da autoridade policial, levando a vitimização secundaria, onde mais uma vez vítima tem seus direitos violados pela impunidade.

Outro problema que dificulta o trabalho de repressão ao crime se deve ao apoio que o criminoso tem de suas famílias, o direito humano que acabam prejudicando a busca por meliantes, e claro que na teoria e no papel e fácil mostrar que direitos humanos não são para defender bandido, mas não pratica e mais difícil ou inviável investigar um crime, por causa das barreiras legais. Temo também que considerar a natureza humana, a pessoa tem características boas, mas também tem as ruins, por exemplo, no Brasil, e difícil ver alguém falando mal de bandido, tem muitos que defendem criminosos, não é natural as pessoas se predisporem a ajudar as pessoas mais inexperientes em qualquer que seja a coisa, quando as pessoas percebem que seu similar e inexperiente nos negócios, no trabalho em questões políticas ou que envolvem dinheiro tiram proveito, abusam da boa-fé dos outros. Usar os outros e algo muito praticado no Brasil. Por isso as escolas deveriam formar pessoas mais cautelosas para o convívio social. Isso para evitar que pessoas de boa-fé sejam enganadas.

A boa vontade não existe no Brasil, ninguém faz nada se não for pressionado a mostrar resultado, como a polícia, nem adianta fazer boletim de ocorrência em delegacia para crimes leve como roubo e furto de celulares, a polícia não faz nada e só perca de tempo ir à delegacia, como explicar isso, muito simples polícia e como uma empresa, cheia de pessoas competindo por cargo e para se dar bem, quando alguém chega com problema à primeira coisa que um oficial da polícia faz e tentar desaconselhar a pessoa a fazer o boletim de ocorrência, a boa e velha malandragem. Quanto mais velha, mais estudada a pessoa e mais esperta fica, como todos sabem no mundo a cada um por si, então quando ocorre o evento criminoso polícia deveria ser firme, deveria agir. A corrupção e a malandragem estão presentes em todas as pessoas, por isso que o crime e a injustiça não podem ser vencidos.

\section{CONCLUSÃO E CONSIDERAÇÕES FINAIS}

O presente artigo tentou demonstrar o que é o crime, lêem de expor o controle social, que pode ser formal e informal, da vítima, e um pouco do funcionamento da polícia brasileira, os problemas e mentalidade das pessoas. Além de buscar explicações ao fato criminoso, critica polícia brasileira aos valores que são repassados de modo errado. No final das contas da para entender que a convivência com a família, com os colegas de trabalho e amigos e o que torna as pessoas boas, para entender o sofrimento e a alegria dos outros e precisa estar perto das pessoas, de forma alguma este artigo tentou desmerecer as 
pessoas, mas somente tentar explicar o evento criminoso voltando às origens do homem ate a vida em sociedade, pois e em grupo que se prende a ser uma boa pessoa.

\section{REFERÊNCIAS}

1 BARATTA, Alessandro. Criminologia crítica e crítica do Direito Penal. 3. Ed. Rio de Janeiro: Revan, 2002.

2 BARATTA, Alessandro. O paradigma do gênero: da questão criminal à questão humana. In: CAMPOS, Carmen (Org.). Criminologia e Feminismo. Porto Alegre: Sulina, 1999.

3 BARATTA, Alessandro. Criminologia crítica e crítica do direito penal. Ed. Rio de Janeiro: Freitas Bastos, 1999.

4 BATISTA, Nilo. Punidos e Mal Pagos - Violência, Justiça, Segurança Pública e Direito Humanos No Brasil de Hoje, 1990, Editora Revan.

AMICO, Carla Campos. Inovações decorrentes da Lei n. 11.464/07. Boletim do Instituto Brasileiro de Ciências Criminais, n.o 176. - São Paulo, 2007.

5 BANDEIRA, Leonardo Costa. Do direito constitucional de recorrer em liberdade. Belo Horizonte: Del Rey, 2003.

6 BATISTA, Nilo. Introdução crítica ao direito penal brasileiro. 9 ed. - Rio de Janeiro: Revan, 2004.

7 BECHARA, Fábio Ramazzani. Legislação penal especial: crimes hediondos, abuso de autoridade, tóxicos, contravenções, tortura, porte de armas e crimes contra a ordem tributária. 2 ed. rev. e atual. - São Paulo: Saraiva, 2006. 